\title{
The Superiority of the Micrographic Surgery Technique in the Surgical Treatment of Facial Basal Cell Carcinomas
}

\author{
Hârceagă O, Baican Corina, Cosgarea Rodica \\ Dermatology Clinic, Regional Clinical Emergency Hospital, Cluj-Napoca, Romania
}

\begin{abstract}
Objective: The aim of this study is to determine the benefits and disadvantages of using micrographic surgery in the treatment of basal cell carcinomas $(\mathrm{BCC})$ of the face. We compared the classic surgery with the micrographic surgery by using a prospective randomized comparative study for two groups of patients.

Methods: Patients included in the study were divided into two groups. The first group was treated by Mohs Surgery. A number of 49 patients who presented 52 tumors were included in this group. In the second group were included 52 patients with 53 tumors. These patients were treated by classic surgery. Patients were scheduled for follow-up and evaluation of efficacy of the two surgical methods.

Results: The mean follow-up was one year for the micrographic surgery group and 1.1 years for the classic surgery group. For the micrographic surgery group we noted zero recurrences and for the classic surgery group we had two (3.7\%) recurrences in two different patients. Treatment time (surgical excision) was 21 minutes for the classic surgery group and 47 minutes for the micrographic surgery group.

Conclusions: Micrographic surgery remains the gold standard for the treatment of BCC at the head level. Micrographic surgery is the only treatment method which is reporting healing rates over $95 \%$ in the majority of studies. A good selection of the cases is mandatory; micrographic surgery should be used for aggressive tumors in difficult location and especially on the face.
\end{abstract}

Keywords: Mohs surgery, basal cell carcinoma, skin cancer surgical treatment, relapse of skin carcinoma

Received: 4 January 2013

\section{Introduction}

Basal and squamous cell carcinoma are the most frequently found skin cancers in the caucasian population. In the last years it has been noticed that the frequency of these types of cancers increased with $10 \%$. Even if these tumors are considered low aggressive cancers because they have a reduced risk of metastasis, they produce a high local morbidity by infiltration and destruction [1]. The treatment of these lesions has to fulfill some important objectives: destruction of tumoral tissue (recurrence appears because of incomplete tumor destruction), healthy tissue sparing, good esthetic result, low treatment cost, because of the high frequency of these tumors.

Basal cell carcinoma (BCC) is found mostly on the sun exposed areas; $80 \%$ from all cases are found on the face and neck, followed by $15 \%$ on the trunk and limbs. There are reports with unusual sites of occurrence for BCC like: axilla, breasts, palm and soles, genitalia. In a review of 1039 cases Sexton et al. [2] showed that the most common histologic forms of BCC are: mixed $38.6 \%$, nodular $21 \%$, superficial $17.4 \%$, micronodular $14.5 \%$ and the rest of $9 \%$ is represented by other forms which are more aggressive, infiltrative, morpheaform, metatypical. The histologic classification of Sexton has correlations with the clinical evolution. Based on this, treatment is chosen regarding the histologic

Correspondence to: Olimpiu Hârceagă

E-mail: olimpiu.harceaga@gmail.com classification, which divides subtypes in two groups: indolent (superficial, nodular) and aggressive (micronodular, infiltrative, morpheaform, metatypical and mixed forms).

Other important factors when choosing the best treatment are the risk factors for subclinical extension: diameter greater than $2 \mathrm{~cm}$, central localization at the face level or at the ear, evolution for a long period of time, perineural and perivascular tumor invasion. Tumors with unclear clinical margins or subclinical extensions are more frequently associated with positive margins after treatment and they have a greater recurrence risk than tumors with clear clinical margins [3].

\section{Therapy selection algorithm}

Non-melanocytic skin tumors are often treated by surgical excision and radiotherapy. The best results in term of low recurrence rates are obtained with surgery, and this is the result of most of the studies published in the scientific literature [4]. The tailored therapy has to comply also with cosmetic considerations and the wishes of the patient.

\section{Classic surgical excision with histopathological margin evaluation}

Surgical excision is done with safety margins of $4 \mathrm{~mm}$ for primary $\mathrm{BCC}$ with a diameter smaller than $2 \mathrm{~cm}$ and clear clinical margins. For spinocellular carcinoma (CSC), safety surgical margins are between 4 and $6 \mathrm{~mm}$. If margins are tumor infiltrated, recommendations are for immediate re- 
excision. "Wait and see" attitude is considered of high risk because of high morbidity and difficult treatment in case of recurrence.

\section{Micrographic surgery. Mohs surgery}

These techniques are using frozen sections for the tumor margin assessment. Sections are made parallel with the skin, different from the classic histology technique, where sections are made perpendicular in a broad leaf fashion from the specimen. Almost total margins control is obtained using these techniques. Micrographic surgery is recommended for high risk carcinoma. There are multiple techniques of micrographic surgery, most studies are referring to the Mohs method, which was the first method described over fifty years ago [5].

\section{Radiotherapy}

There are many controversies regarding the use of radiotherapy (RT) for the treatment of skin carcinoma. Two opposite opinion exist, one which advocates the use of RT in a great number of cases and the second which describes RT as an adjuvant therapy after surgery. The NCCN (U.S. National Comprehensive Cancer Network) guideline recommends a consensus of these two opposite opinions. RT as first intention therapy is reserved for patients over 60 years because of the possible side effects [6]. RT is avoided in genetic syndromes, such as xeroderma pigmentosum, collagenosis, Gorlin's syndrome.

\section{Superficial therapies}

These types of therapies comprise: topical application of 5FU (fluorouracil) or imiquimod, PDT (photodynamic therapy), cryotherapy. Recurrence rates are higher for these therapies, when compared with surgery and radiotherapy [7].

Another group of therapies are new emerging therapies. They comprise systemic therapies, such as Vismodegib, a hedgehog signaling pathway inhibitor. These new therapies are used for Gorlin's syndrome and for metastatic diseases.

The majority of BCC are nodular type and they appear at the facial level in patients over 60 years old. For this type of tumors superficial therapies do not have indications because of the high risk of relapse. RT is not feasible for high volume tumors and for locations close to vital structures, such as the eyeball. The therapy with the highest healing rate reported in the scientific literature, for the BCC, is micrographic surgery $[8,9]$.

\section{Aim}

The aim of this study is to determine the benefits and the disadvantages of using micrographic surgery in the treatment of facial BCC. Classic surgery was compared with micrographic surgery using a prospective randomized comparative study for two groups of patients. BCCs included in the study had to fulfill three criteria from the list of indications for micrographic surgery (Table I). BCCs
Table I. Inclusion criteria

\begin{tabular}{ll}
\hline Relapse & $\begin{array}{l}\text { Incomplete excision or post Mohs surgery } \\
\text { relapse }\end{array}$ \\
Unclear clinical borders & Localization at head level \\
Sclerodermiform type & $\begin{array}{l}\text { Periorificial } \\
\text { Ulcerated tumor }\end{array}$ \\
Diameter greater than $2 \mathrm{~cm}$ & $\begin{array}{l}\text { Cartilage involvement } \\
\text { Immonosuppression by medication }\end{array}$
\end{tabular}

with high risk of relapse were included.

\section{Patients and methods}

The study took place at the Dermatology Clinic ClujNapoca from May 2010 until September 2012. Patients included in the study were divided into two groups.

The first group was treated with micrographic surgery Mohs surgery (MS) method. A number of 49 patients who presented 52 tumors were included in this group. Three patients presented two tumors, the rest of them presented one tumor.

In the second group were included 52 patients with 53 tumors. These patients were treated by classic surgery (CS).

Tumors were excised by four dermatologists and they were histopathologically evaluated by two anatomopathologists.

\section{Inclusion criteria}

We included patients who at clinical inspection presented lesions diagnosed as BCC and the diagnosis had to be confirmed by histology. Tumors had to be on the face and had to have at least two other criteria from Table I.

The criteria presented in Table I are indicating an aggressive tumor behavior, which normally has an indication for micrographic surgery $[10,11]$. Primary tumors with a diameter smaller than $0.3 \mathrm{~cm}$ were not included in the study, because they were considered of low risk no matter what other characteristics they had.

\section{Method}

Patients were seen in the ambulatory unit of the Dermatology Clinic Cluj-Napoca by the dermatology specialist. Patients who presented suspected lesions of BCC and fulfilled the inclusion criteria mentioned above were asked whether they want to participate in the study. If they accepted and signed the acceptance form, they continued the evaluation with the authors of the study. Patients included were assigned to one of the two groups randomly, so that no consecutive patients would be in the same group. If the clinical diagnosis did not correspond with the histopathological diagnosis, the lesion was later excluded.

Patients who were assigned to the Mohs surgery (MS) group had their lesions measured and photographed. Two diameters were noted. Tumor clinical margin was drawn using gentian violet by clinical observation in the operation room under surgical light. Surgical safety margin was established at $2 \mathrm{~mm}$ for this group and marked on the skin before anesthesia was administered. Local anesthesia was 

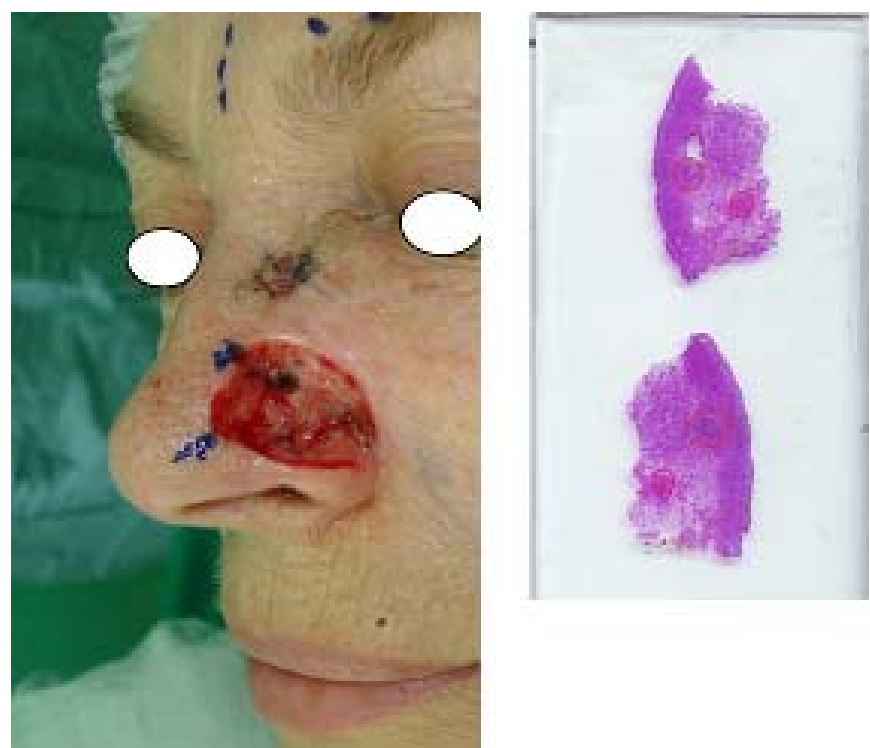

Fig. 1. Defect after two Mohs stages and tumor infiltration seen on the slides after primary excision

used with a mixture of lidocaine and adrenaline 1:200.000. The Mohs protocol was followed, so the first excision had to be made with $2 \mathrm{~mm}$ surgical safety margin [9]. There are no specific recommendations for the depth of excision in the Mohs protocol. For thin tumors the excision was performed until the subcutaneous tissue. For thicker tumors or with infiltrative pattern, the subcutaneous tissue which seemed clinically affected was excised, and in rare cases the underlying fascia was reached.

After skin incisions were made, the 12 o'clock point was marked with a tread on the specimen. This point corresponded in vivo with the superior pole. Skin incisions were made at a $45^{\circ}$ angle, so the resulted specimen had a conic shape with the deep plan smaller than the upper epidermic plan. This shape is important, because specimens with this form allow having the peripherical margin in the same plane with the deep surface [12]. In the histopathology laboratory the specimen was processed according to Mohs surgery technique. Bigger specimens were divided and marked with colors which were drawn on a map. Sections were made at a thickness of $6-8 \mu \mathrm{m}$, parallel with the epidermal layer. Slides were stained with hematoxylineosine (HE) (Figure 1).

Slides were interpreted by the anatomopathologist along with the surgeon to reduce orientation errors. If tumor cells were found on the first slides, the exact position was marked on the map. In this way re-excision was performed at a limited site, exactly where the tumor infiltrated margin was. A Mohs cycle took about 45 minutes. This process was repeated until tumor free slides were found at examination.

Classic surgical excisions (CS) were also done in local anesthesia with lidocaine and adrenaline 1:200.000. Here the surgical margins were set at $4 \mathrm{~mm}$ according to the NCCN guidelines. These margins were used as often as possible, but in cases of vicinity with vital structures e.g. eyelids, eyeball, margins were taken as close as possible to
$4 \mathrm{~mm}$. The superior pole of the specimen was marked with a thread and sent to pathology. In the anatomopathology laboratory the specimens followed the classic paraffin process, which comprises cutting slides from the specimen area where the tumor is close to the surgical margin. This evaluation is made by naked eye. Slides were stained with $\mathrm{H}-\mathrm{E}$ and the result was available in about two weeks. Patients where the excisional margins were infiltrated by tumor were not treated by re-excision; instead this group of patients was followed more closely. If a recurrence was diagnosed, the patients were treated by MS.

Defect reconstruction was done immediately for the CS group. For the MS groups reconstruction was made only after the margins were free of tumor; this meant between a few hours to 2-3 days from the moment of initial excision, according to the number of Mohs stages. Methods of reconstruction used varied from persecundam healing to local flaps for bigger defects. Methods of reconstruction were chosen according to defect characteristics and age, comorbidities, patient wish.

Patients were scheduled for follow-up and the evaluation of efficacy of the two surgical methods was done. Follow-ups were scheduled at every 6 months in the first year and then yearly. The total follow-up duration was set to 5 years. The mean follow-up period was calculated from the time of surgery to the last follow-up visit which the patient attended. Relapses were registered if they were confirmed by biopsy.

For each case total treatment time (duration of excision without reconstruction time) was registered. For the MS the time of each excision from the Mohs stages was summed. For the patients included in the study also the socio-demographic characteristics were noted, which are presented in Table I.

\section{Results}

One-hundred one patients were included in the study from May 2010 to September 2012. In total 105 tumors were treated with both methods. Four patients had two tumors.

The mean age for the CS group was 70 years, interval between 27 and 87 years. In CS group we had 52 patients with 53 tumors, one had two lesions. Seventeen patients were female and 35 male. The mean surface was $0.9 \mathrm{~cm}^{2}$, interval $0.09-2.95 \mathrm{~cm}^{2}$. From the 53 tumors $8(15 \%)$ were incompletely excised and the rest were completly excised

Table II. Characteristics for 8 tumors incomplete excised with CS

\begin{tabular}{lccccc}
\hline Localization & Surface $\left(\mathrm{cm}^{2}\right)$ & Histologic subtype & Sex & Age & Relapse \\
\hline Genian & 0.19 & Baso squamous & M & 76 & No \\
Nose & 1.23 & Baso nodular & M & 79 & No \\
Cheek & 0.19 & Baso superficial & F & 79 & No \\
Nose & 0.20 & Baso nodular & F & 77 & No \\
Preauricular & 0.35 & Baso nodular & M & 78 & Yes \\
Cheek & 0.20 & Baso infiltrative & M & 74 & No \\
Medial & 1.13 & Baso infiltrative & F & 75 & No \\
canthus & & & & & \\
Temporal & 0.20 & Bazo nodular & M & 77 & No \\
\hline
\end{tabular}


Table III. Characteristics of tumors treated with CS

\begin{tabular}{|c|c|c|c|}
\hline \multicolumn{4}{|c|}{ Primary Tumors no. 49 (92.5\%) } \\
\hline Histologic subtype & No. & Localization & No. \\
\hline Nodular & 33 & Cheek & 14 \\
\hline Superficial & 9 & Nose & 12 \\
\hline Infiltrative & 4 & Temporal & 3 \\
\hline \multirow{3}{*}{$\begin{array}{l}\text { Mixed, nodular with metatypic } \\
\text { areas }\end{array}$} & 1 & Frontal & 3 \\
\hline & & Chin & 3 \\
\hline & & Preauricular & 3 \\
\hline Basosquamous & 1 & Retroauricular & 2 \\
\hline \multirow[t]{5}{*}{ CC trichilemal } & 1 & Suborbital & 2 \\
\hline & & Nasolabial fold & 2 \\
\hline & & Inf. eyelid & 2 \\
\hline & & Medial canthus & 2 \\
\hline & & & 1 \\
\hline \multicolumn{4}{|c|}{ Recurrent tumors no. 4 (7.5\%) } \\
\hline Histologic subtype & No. & Localization & No. \\
\hline Nodular & 2 & Nose & 1 \\
\hline Infiltrative & 1 & Nasolabial fold & 1 \\
\hline \multirow{2}{*}{$\begin{array}{l}\text { Mixed, nodular with metatypic } \\
\text { areas }\end{array}$} & 1 & Ear & 1 \\
\hline & & Preauricular & 1 \\
\hline
\end{tabular}

according to the histopathology report. Characteristics of incompletely excised tumors can be seen in Table II.

Histologic subtypes can be seen in Table III. The most frequent subtype was nodular, 34 tumors. The most frequent localization was on the cheek and nose. Four tumors were recurrent, 49 were primary tumors.

In the MS group 49 patients had 52 lesions. Mean age was 66 years, interval between 35 and 97 years. Twenty-two patients were male and they had 24 tumors, 27 patients were female with 28 tumors. Three patients presented two lesions each. Nine (17.3\%) tumors were recurrent, treated before with CS or electrocauterization. Characteristics of recurrent tumors are presented in Table IV.

Patients treated by MS were initially excised with a safety margin of 2-3 mm. After first stage $16(30 \%)$ tumors had been completely excised, 36 tumors had to be re-excised
Table IV. Characteristics of tumors treated with MS

\begin{tabular}{|c|c|c|c|}
\hline \multicolumn{4}{|c|}{ Primary Tumors no. 43 (82.7\%) } \\
\hline Histologic subtype & No. & Localization & No. \\
\hline Nodular & 27 & Nose ala & 14 \\
\hline Infiltrative & 8 & Nose tip & 6 \\
\hline Superficial & 4 & Nose dorsum & 4 \\
\hline Morpheaform & 2 & Infero orbital & 6 \\
\hline $\begin{array}{l}\text { Mixed, nodular with metatypic } \\
\text { areas }\end{array}$ & 1 & $\begin{array}{l}\text { Medial Canthus } \\
\text { Inf. eyelid }\end{array}$ & $\begin{array}{l}3 \\
1\end{array}$ \\
\hline Mixed, nodular with infiltrative & 2 & Sup. eyelid & 1 \\
\hline & & Zygomatic area & 1 \\
\hline & & Nasolabial fold & 3 \\
\hline & & Ear & 1 \\
\hline & & Temporal & 1 \\
\hline & & Preauricular & 1 \\
\hline & & Frontal & 1 \\
\hline \multicolumn{4}{|c|}{ Recurrent tumors no. 4 (7.5\%) } \\
\hline Histologic subtype & No. & Localization & No. \\
\hline Infiltrative & 2 & Nose ala & 5 \\
\hline Nodular & 2 & Medial canthus & 1 \\
\hline \multirow{3}{*}{$\begin{array}{l}\text { Mixed, nodular with metatypic } \\
\text { areas }\end{array}$} & 2 & Ear & 1 \\
\hline & & Temporal & 1 \\
\hline & & Nasolabial fold & 1 \\
\hline Morpheaform & 1 & & \\
\hline Micronodular & 1 & & \\
\hline $\begin{array}{l}\text { Mixed, nodular with infiltrative } \\
\text { type areas }\end{array}$ & 1 & & \\
\hline
\end{tabular}

with another $2-3 \mathrm{~mm}$ at the level of infiltrated margin. After the second excision $47(90.4 \%)$ tumors were completely excised. Five tumors $(9.6 \%)$ needed $7 \mathrm{~mm}$ surgical margin. Two patients were not free of tumor after the third excision, they continued treatment with RT. Localization of tumor infiltration and the number of Mohs stages can be seen in Table V. The characteristics of tumors which needed more than $5 \mathrm{~mm}$ of marginal resection are shown in Table VI.

Follow-up mean period was one year for MS, interval between 2 months the shortest and 1.8 years. For the group

Table V. Localization of tumor cells at the excised specimen margins (spec. $=$ specimen/s)

\begin{tabular}{|c|c|c|c|c|c|c|}
\hline & Depth & Periphery $100 \%$ & $\begin{array}{l}\text { Lat. margins partially } \\
\qquad 1 / 2\end{array}$ & $\begin{array}{l}\text { Depth }+ \text { margins } \\
\text { partially } 1 / 2\end{array}$ & $\begin{array}{c}\text { Depth }+ \text { margins } \\
100 \%\end{array}$ & Tumor free \\
\hline $\begin{array}{l}\text { Excision I } \\
2-3 \mathrm{~mm}\end{array}$ & 10 spec. & 2 spec. & 14 spec. & 7 spec. & 3 spec. & 16 spec. \\
\hline $\begin{array}{l}\text { Excision II } \\
4-5 \mathrm{~mm}\end{array}$ & 3 spec. & - & 2 spec. & - & - & $31 \mathrm{spec}$. \\
\hline $\begin{array}{l}\text { Excision III } \\
7 \mathrm{~mm}\end{array}$ & 1 spec. & - & $1 \mathrm{spec}$. & - & - & 3 spec. \\
\hline
\end{tabular}

Table VI. Characteristics of 5 tumors which needed three Mohs stages

\begin{tabular}{|c|c|c|c|c|c|c|c|c|}
\hline Histo subtype & No. & Localization & No. & Surface & No. & $\begin{array}{l}\text { Primary tumor vs } \\
\text { relapse }\end{array}$ & Infiltrate localization & No. \\
\hline Nodular & 2 & Nose ala & 2 & $>2 \mathrm{~cm}$ & 2 & 2 relapses & Depth & 3 \\
\hline Morpheaform & 1 & Medial canthus & 1 & $<1 \mathrm{~cm}$ & 2 & 3 primaries & Periphery & 2 \\
\hline \multirow[t]{2}{*}{ Mixed nodular + infiltrative } & 2 & Inf. eyelid & 1 & $1-2 \mathrm{~cm}$ & 1 & & & \\
\hline & & Nasofacial fold & 1 & & & & & \\
\hline
\end{tabular}



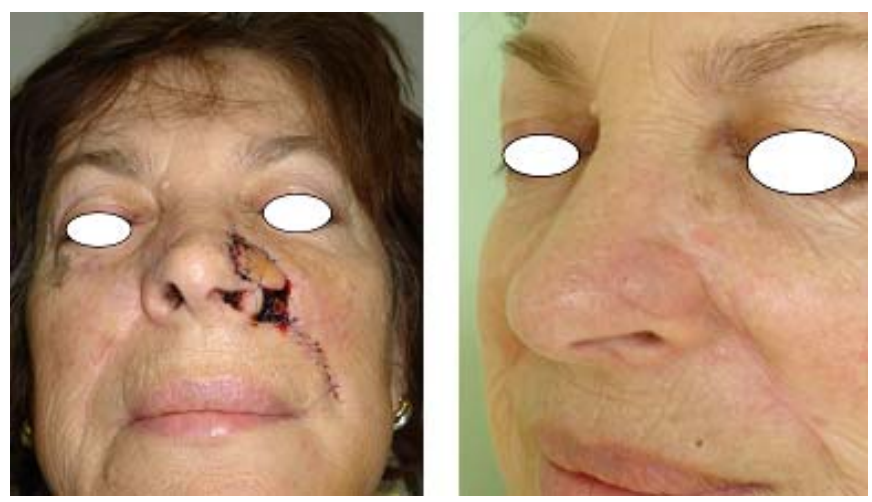

Fig. 2. Defect covered by an island pedicle flap. Postoperative aspect after one month

treated with CS follow-up mean period was 1.1 years, interval between 4 months and 2.3 years. All patients were at least once evaluated post treatment. Compliance for follow-up visits was low, 6 patients were lost, they didn't complete any visit of follow-up, and they were not included in the final results.

The the most frequently used reconstruction method for both groups taken together and separately was local flap (Figure 2). The second most frequent method was skin graft, and then combined methods.

Two relapses (3.7\%) in the CS group and zero relapses in MS until September 2012 were registered, but the follow-up will continue for 5 years in both groups. Relapses were primary tumors, nodular and infiltrative subtypes and both of them were localized at the nose level. Nodular subtype presented tumor infiltration of the margins at the histopathology examination. The second patient was free of tumor according to the histopathology report. These two patients were further treated by MS and became part of this group.

Treatment time (surgical excision) was 21 minutes for the CS group and 47 minutes for the MS group.

\section{Discussions}

The aim of the study was to compare the post therapeutic outcome after CS and MS, and to emphasize the best treatment method for aggressive facial BCC. Results regarding recurrence after each surgical method discussed here are not conclusive, because the follow-up period has to be minimum two years in each group. The majority of recurrences appear in the first two years after the treatment [13]. For some authors the recurrence peak is at two years post treatment. For others like Rowe et al. less than $1 / 3$ of recurrence cases are evident in the first year, and only half of the cases will appear in the first two years post treatment. Two thirds of the recurrences are diagnosed in the first 3 years.

In our study the mean follow-up was one year for MS group and 1.1 years for the CS. For the MS group zero recurrences were noted and for CS group we had two, 3.7\%, recurrences in two different patients.

For the CS recurrence rates reported in the literature, they can vary widely. In a review Thissen et al. did a meta- analysis from three articles which accounted for more than 1500 patients. Recurrence rate calculated at five years was between $3.2-8 \%$ for primary tumors [14]. In a study dedicated to BCC relapses after CS, Silverman et al. showed the relapses rates for each region on the body: for the extremities and body rates were $0.7 \%$, and for head and neck depending on the diameter: $<6 \mathrm{~mm} \mathrm{3.2 \% ,6-9} \mathrm{mm} 8 \%$, $>10 \mathrm{~mm} \mathrm{9 \%} \mathrm{[15].}$

In our study, surgical safety margin was $4 \mathrm{~mm}$ for the CS group. In most of the studies cited in the scientific literature this margin was $3 \mathrm{~mm}[15,16]$. This safety margin of $4 \mathrm{~mm}$ can produce lower recurrences on long term. For the $4 \mathrm{~mm}$ margin tumor clearance is achieved in $95 \%$ of the cases where diameter was smaller than $2 \mathrm{~cm}$ [17]. These results were also given by numerous studies which used micrographic surgery to estimate tumor clearance for a certain safety surgical margin. Considering these results for a $4 \mathrm{~mm}$ margin using CS treatment method, the relapse should be less than 5\% after two years follow-up. In our study the mean relapse rate after 1 year follow-up was $3.7 \%$. In a study of over 844 cases in France which used $4 \mathrm{~mm}$ safety margin and CS for tumors with a mean diameter of $13 \mathrm{~mm}$ localized over the entire body, the relapse rate was $3.8 \%$. The mean follow-up was 36 months [18].

A different approach in our study compared with others was the management of the cases with tumor infiltration of the margins after CS. In our study these cases were observed and treated by MS only if a histologically confirmed relapse occurred. In other studies, Smeets et al., who reported lower relapse rates (3\% at 30 months) [19], additional excision was performed with a $3 \mathrm{~mm}$ margin if margins were infiltrated. If margins were still tumor positive, the patient was switched to MS. In this way relapses were reduced substantially. Relapses can appear in cases where margins were false negative and further treatment was not needed. False negative results are possible for CS because the histology is classic broad leaf type. According to some studies, the rate of false negative histologic results is 20 $22 \%$ for CS [15]. In fact, the main differences between the two methods of surgical treatment are the number of false negative results from the histological examination, which is lower for the MS method. The difference is given by the percent of margin examination, which is around $1 \%$ for CS and almost $100 \%$ for MS.

Relapse in cases with tumor infiltration of margins is an issue discussed a lot in the scientific literature. Some studies are reporting rates between $8-43 \%$ from the tumor positive cases. In a meta-analysis which comprises of 86 studies Gastman et al. shows the mean rate of relapse is $27 \%$ from the cases with positive margins. In this study were included 14.000 cases and the surgical safety margin was 3-4 mm [15,16].

In our study $15 \%$ (8 cases) of the tumors excised by CS had infiltrated margins and in the scientific literature rates reported are between $12-43 \%$ [20]. We had 2 relapses 
from which one case with tumor infiltrated margins on the initial treatment; this means a rate of $12.5 \%$ relapse from tumor positive cases, which is much lower than any other report in the literature. This is without any doubt because of the short follow-up in our study.

In our study the most frequent tumor localization with positive margins were: nose, cheek, medial canthus, temporal region and ear. These locations correspond with the reports from literature, as high risk for relapse and incomplete excision.

Not all the patients with positive margins will relapse. It can be considered that some histological reports are false positive and so the number of cases with positive margins is artificially increased. This can happened if tumor cells are tangent to the surgical margin. Another explanation can be destruction of tumor cells by post-surgery inflammation and healing process $[15,21]$.

Which are the factors for a high risk relapse in patients with tumor positive margins? Localization, size, histologic subtypes are the most important predictive factors [20]. In our group treated by CS, from 8 tumors with positive margins, $3(37.5 \%)$ had an aggressive histologic subtype with a localization that corresponded with dates reported in the literature, for example the nose which is the most common location (Table III). Size of the tumors with positive margins was smaller than the mean size; this can be explained by the small group and the short followup period.

At the re-excision of the tumor positive margins, tumor cells are found in $50 \%$ of the cases [22]. Another study on $1400 \mathrm{BCC}$ treated with CS found tumor cells in the re-excision specimens in $28 \%$ of the cases [23]. Limitations for the majority of studies are the classic histological method of examination. For this reason we believe that the actual rates on this issue are higher than those presented, but not $100 \%$.

In case of incomplete excision by $\mathrm{CS}$ the attitude recommended by the majority of authors is re-excision. By immediate re-excision avoidance of relapse is achieved. Yet we need to have a tailored approach for each case because less than half of the positive BCC will relapse.

Relapse rate of the tumors treated by MS is $1-2 \%$ [19, 14]. This low relapse rate is assured by complete tumor excision. Through total margins assessment false negative results are reduced. Lesions are excised little by little, obtaining total tumor excision. The difference of relapse rates between CS and MS are favorable to MS in most of the studies. This high efficiency for MS is secondary to histologic examination of almost $100 \%$ of the margins. In our study recurrence was 0 for this group, after one year follow-up.

The number of MS stages necessary for free tumor margins including initially excision is 1,78 similar to literature dates [19]. The initial surgical safety margin for MS was 2-3 $\mathrm{mm}$ and for each stage another $2 \mathrm{~mm}$ was excised from the tumor infiltrated area. After the first excision with $2-3 \mathrm{~mm}, 30 \%$ of the patients were free of tumor. After the second stage, which meant a total of $4-5 \mathrm{~mm}$ of surgical margin, $90.4 \%$ of the patients were free of tumor. Five patients needed three stages of MS, meaning $7 \mathrm{~mm}$ of safety surgical margin. In our study two patients were positive even after three stages. These patients were treated with RT (local radiotherapy) for disease control. These tumors were located on the medial canthus and nasolabial fold. The patient with nasolabial fold tumor was treated several times by CS before MS. Probably because of reconstruction with flaps, tumor became multicentric and it was difficult to be treated by MS. The second patient had a $2.3 \mathrm{~cm}$ diameter tumor located on medial canthus. $\mathrm{He}$ had three stages of MS, but tumor infiltrate was still found in depth. For total tumor excision sacrifice of the medial canthal tendon and of the inferior lacrimal canaliculus was needed and the patient refused the intervention. The patient was directed to RT.

Tumor characteristics which needed three excisions with MS are presented in Table VI. They present aggressive histologic subtypes (mixed, infiltrative, morpheaform) and locations with high risk for subclinical invasion (nose, medial canthus, inferior lids, nasolabial fold). Dimensions were higher than the group average. Our dates were similar with those from the scientific literature.

The most frequent localization was on the nose, 42 tumors $(40 \%)$ in both groups. Other studies with bigger number of patients are reporting nose as the most frequent localization $[24,25]$. The nose is also a risk factor for subclinical infiltration and recurrence [26]. The nose localization being the most frequent, local flap was the most used method of reconstruction because these produces the best aesthetic results, much better than skin graft or persecundam healing.

Males had a higher incidence of BCC and in our study. Tumors which appeared in males represented 56\% from the total number of patients [27].

Two patients who presented BCC from the MS group presented also melanoma. Some studies are investigating a link between melanoma and BCC and it is demonstrated that patients with $\mathrm{BCC}$ have a higher risk for developing melanoma [28].

\section{Conclusions}

After a follow-up of 1 year, the relapse for the MS group is zero and the relapse for CS is $3.7 \%$. This is an intermediate result, because a final conclusion is to be issued after a minimum of two years follow-up. Even so, our study demonstrates the superiority of MS for treatment of BCC of the face skin. The main disadvantages for MS are: cost and duration. The mean time for the MS was 47 minutes and for CS 21 minutes. This is the excision time only; reconstruction time was not included, because this should be the same for any surgical method for defects with an equal diameter.

MS remains the gold standard for the treatment of BCC at the head level. MS is the only treatment method which 
reports healing rates over $95 \%$ in the majority of studies. A good selection of the cases is mandatory; MS should be used for aggressive tumors in difficult locations and especially on the face.

\section{References}

1. Robinson JK, Dahiya M. Basal cell carcinoma with pulmonary and lymph node metastasis causing death. Arch Dermatol. 2003;139:643-48.

2. Sexton M, Jones DB, Maloney ME. Histologic pattern analysis of basal cell carcinoma: study of a series of 1039 consecutive neoplasms. J Am Acad Dermatol. 1990;23:1118-26.

3. Walling HW, Fosko SW, Geraminejad PA, Whitaker DC, Arpey CJ. Aggressive basal cell carcinoma: presentation, pathogenesis, and management. Cancer Metastasis Rev. 2004;23:389-402.

4. Bath-Hextall F, Bong J, Perkins W, Williams $H$. Interventions for basal cell carcinoma of the skin: systematic review. BMJ. 2004 Sep 25;329(7468):705. Epub 2004 Sep 13.

5. Pennington BE, Leffell DJ. Mohs micrographic surgery: established uses and emerging trends. Oncology (Williston Park). 2005 Aug;19(9):1165-71; discussion 1171-2, 1175.

6. Neville JA, Welch E, Leffell DJ. Management of nonmelanoma skin cancer in 2007. Nat Clin Pract Oncol. 2007 Aug;4(8):462-9.

7. Rhodes LE, de Rie MA, Leifsdottir R, Yu RC, Bachmann I, Five-year followup of a randomized, prospective trial of topical methyl aminolevulinate photodynamic therapy vs surgery for nodular basal cell carcinoma. Arch Dermatol. 2007 Sep;143(9):1131-6.

8. Rowe DE, Carroll RJ, Day CL, Jr. Mohs surgery is the treatment of choice for recurrent (previously treated) basal cell carcinoma. J Dermatol Surg Oncol 1989;15:424-431.

9. Shriner DL, McCoy DK, Goldberg DJ, Wagner RF Jr. Mohs micrographic surgery. J Am Acad Dermatol. 1998 Jul;39(1):79-97.

10. Minton TJ. Contemporary Mohs surgery applications. Curr Opin Otolaryngol Head Neck Surg. 2008 Aug;16(4):376-80. Review.

11. Drake LA et al. Guidelines of care for Mohs micrographic surgery. American Academy of Dermatology. J Am Acad Dermatol. 1995 Aug;33(2 Pt 1):271-8.

12. Lane JE, Kent DE. Surgical margins in the treatment of nonmelanoma skin cancer and mohs micrographic surgery. Curr Surg 2005;62:518-526.

13. Richmond JD, Davie RM. The significance of incomplete excision in patients with basal cell carcinoma. Br J Plast Surg. 1987 Jan;40(1):63-7.
14. Thissen MR, Neumann MH, Schouten LJ. A systematic review of treatment modalities for primary basal cell carcinomas. Arch Dermatol. 1999 Oct;135(10):1177-83. Review.

15. Silverman MK, Kopf AW, Bart RS,Recurrence rates of treated basal cell carcinomas. Part 3: Surgical excision. J Dermatol Surg Oncol. 1992 Jun;18(6):471-6.

16. Gulleth Y, Goldberg N, Silverman RP, Gastman BR. What is the best surgical margin for a Basal cell carcinoma: a meta-analysis of the literature. Plast Reconstr Surg. 2010 Oct;126(4):1222-31.

17. Wolf DJ, Zitelli JA: Surgical margins for basal cell carcinoma. Arch Dermatol. 1987;123:340-344.

18. Staub G, Revol M, May P. 2007 Oct 24. Excision skin margin and recurrence rate of skin cancer: a prospective study of 844 cases. Ann Chir Plast Esthet. 2008 Oct;53(5):389-98. Epub

19. Smeets NW, Krekels GA, Ostertag JU Surgical excision vs Mohs' micrographic surgery for basal-cell carcinoma of the face: randomised controlled trial. Lancet. 2004 Nov 13-19;364(9447):1766-72.

20. Berlin J, Katz KH, Helm KF, Maloney ME. The significance of tumor persistence after incomplete excision of basal cell carcinoma. J Am Acad Dermatol. 2002 Apr;46(4):549-53.

21. Sei JF. Marges d'exérèse et reprise dans les carcinomes cutanés. Ann Dermatol Venereol 1997;124:421-426.

22. Wilson AW, Howsam G, Santhanam V, et al. Surgical management of incompletely excised basal cell carcinomas of the head and neck. $\mathrm{Br} \mathrm{J}$ Oral Maxillofac Surg. 2004;42:311-314.

23. Bogdanov-Berezovsky A, Cohen A, Glesinger R, Clinical and pathological findings in reexcision of incompletely excised basal cell carcinomas. Ann Plast Surg. 2001 Sep;47(3):299-302.

24. Robinson JK, Fisher SG. Recurrent basal cell carcinoma after incomplete resection. Arch Dermatol. 2000;136:1318-24.

25. Goldberg DP. Assessment and surgical treatment of basal cell skin cancer. Clin Plast Surg. 1997 Oct;24(4):673-86.

26. Newman JC, Leffell DJ. Correlation of embryonic fusion planes with the anatomical distribution of basal cell carcinoma. Dermatol Surg. 2007 Aug;33(8):957-64; discussion 965.

27. Miller DL, Weinstock MA. Nonmelanoma skin cancer in the United States: incidence. J Am Acad Dermatol. 1994 May;30(5 Pt 1):774-8.

28. Chen J, Ruczinski I, Jorgensen TJ, et al. Nonmelanoma skin cancer and risk for subsequent malignancy. J Natl Cancer Inst. 2008 Sep 3;100(17):1215-22. Epub 2008 Aug 26. 